\title{
Severe personality disorder - whose responsibility?
}

\author{
R. CAWTHRA and R. GIBB
}

Should personality disordered individuals receive treatment within today's mental health services? The debate often follows episodes of aggression towards staff or patients by personality disordered individuals receiving treatment in hospital, and more recently where the general public have been affected. The subjects of personality disorder and psychopathy in particular have long evoked strong emotions which make clarity of thought difficult and psychiatry unclear of its position.

\section{DIAGNOSIS AND TREATABILITY}

The diagnostic terms to describe personality disorders have been regularly changed or revised. The term psychopathic is often used interchangeably with terms such as antisocial personality disorder and dis-social personality disorder, although the legally defined term psychopathic disorder has been used to denote severe personality disorders in general, and attention has been drawn to the considerable overlap between different diagnostic categories (Coid, 1992).

A significant proportion of patients admitted to general psychiatric wards have a dual diagnosis of mental illness and personality disorder (Cutting et al, 1986). It is accepted by most clinicians that those with a comorbid Axis I diagnosis legitimately qualify for psychiatric treatment. In addition, a spectrum of severity within the category of personality disorder exists, with those in the milder range being more likely to benefit from treatment (Stone, 1993). Personality disorder in a general psychiatric ward tends to be at the severe end of this spectrum and is associated with severe behavioural disturbance (Dowson et al, 1997).

In academic circles, attention has continued to be drawn to the problems involved in the assessment and treatment of personality dysfunction. Approaches to treatment have tended to be based upon an optimistic view that personality disorders are amenable to psychotherapeutic intervention (Kernberg, 1984; Hartland, 1991; Shearer \& Linehan, 1994) or biological treatments (Stein, 1994). Some advocate further research, arguing that personality disorder cannot be regarded as untreatable as there is insufficient evidence to enable firm conclusions to be drawn (Dolan \& Coid, 1993).

The issue of treatability has been recognised within the Mental Health Act (England and Wales), which requires that the compulsory treatment of an individual with psychopathic disorder must either "alleviate or prevent a deterioration of his condition". Uncertainty continues about the criteria for determining benefit from treatment. In Scotland there is less specificity as personality disorder is not defined in the Mental Health Act, allowing more scope for clinicians to refuse to offer treatment. The possibility of imposing a hospital direction in addition to a prison sentence, collectively referred to as the 'hybrid order', is an attempt to provide a workable solution when treatability is difficult to determine within a forensic setting (Reed, 1996; Eastman, 1997).

\section{ISSUES OF RISK}

When the judiciary turn to psychiatry to protect the public from individuals who threaten serious violence, they sometimes acknowledge the limitations of the criminal justice system, and seek treatment or containment from psychiatric services to satisfy the demands from society for protection. This is in contrast with other views about the appropriateness of psychiatry responding in this way.

The Royal College of Psychiatrists has produced its own report on the risk posed by psychiatric patients, but that document is not explicit about the risk associated with personality disorder (Royal College of Psychiatrists Special Working Party on Clinical Assessment and Management of Risk, 1996). Similarly a recent BJP supplement on risk assessment steers clear of making definitive statements on this specific area (Duggan, 1997). Clinicians using the Care Programme Approach and the Guidelines on Discharge of Mentally Disordered People and their Continuing Care in the Community - HSG (94) 27 Para 20, may be left with some uncertainty about their application in the area of severe personality disorder.

\section{DISSENTING VOICES}

Many professionals who advocate treatment are vociferous in articulating their view, and are turned to by those eager to obtain solutions. Nevertheless, many practising clinicians remain sceptical about treatment. While recognising the high quality work done to understand psychopathic disturbance (Hart \& Hare, 1996) and personality disorder in general, they are of the opinion that these contributions are remote from general psychiatry. They believe that the treatment of personality disorder requires lengthy and intensive treatment, which is of marginal benefit. This treatment absorbs considerable clinical and financial resources, often with a damaging impact on services and the staff working in them. Where personality disordered individuals are treated with mentally ill patients they commonly have a negative, if not damaging, impact on other patients and their treatment. Alongside this is a well-established view that personality disorder tends to mature with the passage of time in the absence of treatment interventions. There is a need for claims of therapeutic success within the field of personality disorder to be rigorously appraised.

\section{ACCEPTING RESPONSIBILITY}

A central theme in the well known writings of Thomas Szasz has been to emphasise the dangers of medicalisation of those with mental disorder and the removal of personal responsibility from those who behave in an antisocial way. The issue of responsibility is also central to treatment in therapeutic communities, where individuals are challenged with regard to their socially damaging behaviours. The focus on the risks 
posed by those with disturbed personalities treated in the special (high security) hospitals raises again the question of whether they should be held responsible for their actions or should receive 'treatment'. The inability of modern psychiatric services to treat violent and perverse individuals is often not acknowledged. Instead, clinicians are sometimes held accountable to sustain a belief that these patients can be managed and returned to society.

\section{PSYCHODYNAMIC ISSUES}

Currently only a minority of personality disordered individuals are admitted to specialised forensic settings. The vast majority gain entry to more traditional general psychiatric services. During such admissions, it is commonplace for there to be episodes of violence, threats to staff and disruption of the clinical ward milieu. The behaviour exhibited by those with severe personality disorder can create strife for medical and nursing staff who may become emotionally exhausted and traumatised (Health and Safety Executive, 1987; Shepherd, 1994). Projective mechanisms with denial, maintain the personality disordered patients' lack of emotional concern for their devastating impact on those engaged in trying to help them. Staff working within general psychiatric settings are often insufficiently trained to deal with these behaviours and may consequently react by acting out these powerful dynamics elsewhere within the care system with damaging consequences (Kernberg, 1984).

Some recent contributors offer to provide support through education, and suggest possible assessment for entry to more highly specialised in-patient psychotherapeutic treatment programmes (Norton \& Hinshelwood, 1996). They advocate that the mainstay of therapeutic work will continue to be provided from within a general psychiatric setting supported by the use of treatment contracts, psychotherapeutic supervision and support for staff. This may be misleading in giving an impression that, if more resources of this type were available, personality disorder will be effectively treated.

\section{CONSEQUENCES OF NOT PROVIDING TREATMENT}

A decision has to be made about who is responsible for this group of individuals and their behaviour. A White Paper on a new Irish Mental Act has excluded personality disorder as a criterion for involuntary detention, which was welcomed by the Irish Division of the Royal College of Psychiatrists (Webb, 1997). This issue of responsibility also needs to be addressed by those commissioning psychiatric services who are increasingly questioning the provision of services for personality disorders in the absence of clear evidence on the benefits of treatment.

Difficult and disturbed individuals within society will continue to present a challenge but this does not mean that psychiatry should necessarily provide treatment for those society finds unmanageable and unacceptable by reason of their behaviour. Psychiatry is open to criticism if it decides not to treat this group, with those who advocate treatment accusing the profession of uncaringly leaving these individuals in society where they continue to pose problems. The duty to care argument continues to be applied by those who expect a solution to be found to the problem of violence and aggression from those with personality disorder. This may lead to public anger directed towards psychiatry for not taking responsibility (Gunn, 1992). Psychiatry should not be paralysed by these expectations. To expect psychiatry to contain those with severe personality disorder for long periods of time when there is no realistic prospect of significant therapeutic benefit seems a misuse of precious hospital resources. It is therefore advocated that alternatives to a medical or psychiatric response are examined rather than a passive acceptance of the status quo.

If we are to respond to those who advocate that psychiatry has a role in containing this group, it could be by providing assessment and treatment from within the expanding field of forensic psychiatry where increasing expertise may be developed, and where there is the availability of appropriate physical containment in more secure environments. An over-stretched general psychiatric service attempting to care for the severely mentally ill with inadequate resources and a diminishing number of beds is now prioritising its role and targeting its resources on those patients suffering from mental illness (Department of Health, 1994, 1997). Can it continue to take responsibility for patients with severe personality disorder in the absence of mental illness?

\section{FIFTY YEARS ON}

The clarity with which Sir David Henderson wrote about the treatment of 'Psychopathic states' may continue to guide our thinking (Henderson, 1951).

\begin{abstract}
-...Socially everyone knows that the persons who form this group constitute a very serious problem. The reason is that neither medicine nor the law nor our social organisation have been able to make adequate provision for them in our daily work. In the ordinary mental hospital such persons are a source of constant trouble and anxiety. They disturb the other patients, they upset the medical and nursing staff and they lead a selfish, individualistic existence which brings them into conflict with their fellow patients",
\end{abstract}

Little has changed in 50 years and we face the same difficult issues of treatment and responsibility for this group which continue to raise challenging questions for the criminal justice system, psychiatry, the wider society and the individuals themselves.

\section{REFERENCES}

Coid, J.W. (1992) DSM-1ll diagnosis in criminal psychopaths: a way forward. Criminal Behovour and Mental Health, 2, 78-94.

Cutting, J., Cowen, P. J., Mann, A. H., et al (1986) Personality and psychosis: use of a standardised assessment of personality. Acto Psychiotrica Scondinavico. 73. $87-92$.

Department of Health (1994) The Health of the Nation. Key Area Handbook - Mental liliness (2nd edn). London: HMSO

- (1997) The Health of the Notion. The Spectrum of Core - Local Services for People with Mental Health Problems. London: HMSO

Dolan, B. \& Coid, J. (1993) Psychopothic and Antisocial Personality Disorders. Treatment and Research lssues. London: Gaskell.

Dowson, J. H., Sussams, P. \& Grounds, A.T. (1997) Characteristics of in-patients without psychosis. Psychiatric Bulletin, 21, 553-556.

Duggan, C. (ed.) (1997) Assessing risk in the mentally disordered. British journal of Psychiotry, 170 (suppl. 32). $1-39$

Eastman, N. (1997) Hybrid justice: proposals for the mentally disordered in the Crime (Sentences) Bill. The ethical, legal and health services cost implications. Psychiotric Bulletin, 21. 129-131.

Gunn, J. (1992) Personality disorders and forensic psychiatry. Criminal Behavour and Mental Health. 2. 202-211.

Hart, S. D. \& Hare, R. D. (1996) Psychopathy and antisocial personality disorder. Current Opinion in Psychiatry, 9. 129-132

Hartland, S. (1991) Supportive psychotherapy, in Textbook of Psychotherapy in Psychiatnc Proctice (ed.) Holmes), pp. 213-235. London: Churchill Livingstone.

Health and Safety Executive (1987) Violence to Stoff in the Health Service: London: HMSO 
Menderson, D. K. (1951) Psychopathic states. British Journal of Delinquency. II. 84-87.

Kernberg, O. (1984) Severe Personality Disorders Psychotheropeutic Strategies. New Haven: Yale University Press.

Norton, K. Hinshelwood, R. D. (1996) Severe personality disorder. Treatment issues and selection for in-patient psychotherapy. British journal of Psychiatry. 168. $723-731$

Reed, J. (1996) Psychopathy - a clinical and legal dilemma. British journal of Psychiatry. 168, 4-9.

Royal College of Psychiatrists Special Working Party on Clinical Assessment and Management of Risk (1996) Assessment and Clinical Monogement of Risk of Horm to Other People. Council Report CR 53. London: Royal College of Psychiatrists.

Shearer, E. N. \& Linehan, M. (1994) Dialectical behaviour therapy for borderline personality disorder:

RICHARD CAWTHRA, MRCPsych, Special Care and Rehabilitation Services. St Nicholas Hospital, Newcastle upon Tyne: ROBERT GIBB, MRCPsych, Department of Forensic Psychiatry. University of Newcastle upon Tyne

Correspondence: Dr Richard Cawthra. Consultant Psychiatrist. Special Care and Rehabilitation Services, St Nicholas Hospital, Jubilee Road. Gosfor th. Newcastle uponTyne NE3 3 XT

(First received I September 1997, final revision 23 January 1998, accepted 27 January 1998)

theoretical and empirical foundations. Acto Psychictnca Scondinonco, 89 (suppl. 379), 61-68.

Shepherd, J. (ed.) (1994) Violence in Health Core - A Practical Guide to Coping wth Violence and Caring for Victims. Oxford: Oxford Medical Publications.

Stein, G. (1994) Physical treatments of the personality disorders. Current Opinions in Psychiatry. 7. 129-136.
Stone, M. (1993) Abnormality to Personality - Within and Beyond the Realms of Treatment. New York: Guilford Press.

Webb, M. (1997) Republic of Ireland: White Paper on a new Mental Health Act. Response of the Irish Division of the Royal College of Psychiatrists. Psychiotric Bulletin. 21. 307-3II. 